\title{
Endocytosis of HIV-1 activates plasmacytoid dendritic cells via Toll-like receptor- viral RNA interactions
}

\author{
Anne-Sophie Beignon, ${ }^{1}$ Kelli McKenna, ${ }^{1}$ Mojca Skoberne, ${ }^{1}$ Olivier Manches, ${ }^{1}$ Ida DaSilva, ${ }^{1}$ \\ Daniel G. Kavanagh, ${ }^{2}$ Marie Larsson, ${ }^{1}$ Robert J. Gorelick, ${ }^{3}$ Jeffrey D. Lifson, ${ }^{3}$ and Nina Bhardwaj ${ }^{1}$ \\ ${ }^{1}$ New York University School of Medicine, New York, New York, USA. 2Partners AIDS Research Center, Massachusetts General Hospital and \\ Harvard Medical School, Boston, Massachusetts, USA. ${ }^{3}$ AIDS Vaccine Program, Science Applications International Corporation-Frederick Inc. \\ National Cancer Institute, Frederick, Maryland, USA.
}

\begin{abstract}
HIV-1 directly activates human plasmacytoid DCs (pDCs) by upregulating the expression of costimulatory and MHC molecules and maturation markers, increasing $T$ cell stimulatory activity, and inducing the production of type I interferons and TNF- $\alpha$. A consequence of this activation is the bystander maturation of myeloid DCs and overall enhancement of antigen-presenting function. However, little is known about the mechanism(s) of $\mathrm{pDC}$ activation by HIV-1. Here we demonstrate by in vitro studies that IFN- $\alpha$ production by $\mathrm{pDC}$ in response to HIV-1 requires at least 2 interactions between the cell and virus. Initially, envelope-CD4 interactions mediate endocytosis of HIV-1, as demonstrated through the use of inhibitors of binding, fusion, endocytosis, and endosomal acidification. Subsequently, endosomally delivered viral nucleic acids, particularly RNA, stimulate pDCs through TLRs, as activation is reproduced with purified genomic RNA but not viral RNA packagingdeficient HIV-1 and blocked with different inhibitory TLR ligands. Finally, by using genetic complementation, we show that TLR7 is the likely primary target. Viral RNA rather than DNA in early retrotranscripts appears to be the active factor in HIV-1 that induces IFN- $\alpha$ secretion by $\mathrm{pDCs}$. Since the decline in pDCs in chronic HIV-1 infection is associated with high viral loads and opportunistic infections, exploiting this natural adjuvant activity of HIV-1 RNA might be useful in the development of vaccines for the prevention of AIDS.
\end{abstract}

\section{Introduction}

DCs are bone marrow-derived professional APCs with the capacity to stimulate immune responses. The 2 subsets of human DCs characterized in blood so far, myeloid DCs (MDCs) and plasmacytoid DCs (pDCs), are distinguished by their phenotype and function. MDCs are the most potent APCs for priming of T cell responses, while pDCs induce innate antimicrobial immune responses through production of type I IFNs (1). They differ in other aspects, including differential expression of C-type lectin receptors (CLRs) and TLRs. Studies have demonstrated that TLR7 mRNA is expressed by both blood-derived pDCs and MDCs, whereas TLR8 mRNA is restricted to MDCs (2-6). In addition, pDCs are the only human DC subset expressing TLR9.

In acute viral infections, a transient decline in blood pDCs is typically observed. Chronic infections due to HIV-1, HCV, human T cell leukemia virus type I, herpes simplex virus (HSV), and Dengue virus can lead to decreased levels of blood pDCs, which have been associated with illness severity (7-10). During chronic HIV-1 infection, reduced blood pDC frequency correlates with high viral load, reduced CD4 count, and susceptibility to opportunis-

Nonstandard abbreviations used: Baf A1, bafilomycin A1; CCD, cytochalasin D; CLR, C-type lectin receptor; DC-SIGN, DC-specific ICAM-3-grabbing nonintegrin; DMA, dimethyl amiloride; DOTAP, N-[1-(2,3-dioleoyloxy)propyl]-N,N,N-trimethylammonium methyl-sulfate; HSV, herpes simplex virus; MDC, myeloid DC; NC, nucleocapsid; ODN, oligodeoxyribonucleotide; ORN, oligoribonucleotide; PDC, plasmacytoid DC; pNL4-3, plasmid DNA encoding HIV- $1_{\mathrm{NL} 4-3}$; ssRNA, single-stranded RNA; VSV, vesicular stomatitis virus.

Conflict of interest: The authors have declared that no conflict of interest exists.

Citation for this article: J. Clin. Invest. 115:3265-3275 (2005).

doi:10.1172/JCI26032. tic infections, and antiretroviral therapy only partially reverses this decline (11-19). In contrast, the number of $\mathrm{pDCs}$ appears to be higher in long-term survivors compared with healthy donors (20). pDC loss in blood of chronically infected individuals has been attributed to cell death and/or to a failure of bone marrow progenitors to differentiate into pDCs. Recently, we showed that human blood pDCs but not MDCs undergo phenotypic and functional activation upon exposure to HIV-1 (21). This process is characterized by upregulation of maturation markers such as CD83, CCR7, and costimulatory molecules. In addition, HIV-1activated $\mathrm{pDCs}$ produce IFN- $\alpha$ and TNF- $\alpha$, migrate in response to CCL19, and, in coculture, stimulate the bystander maturation of MDCs. This HIV-1-induced maturation of both DC subsets may partly explain their disappearance from blood of $\mathrm{HIV}^{+}$subjects as they migrate to lymph nodes. As preservation of $\mathrm{pDC}$ and thereby MDC functions would be essential to maintaining antiviral immune responses, further characterization of the nature of pDC-virus interactions is necessary.

To date, little is known regarding the mechanisms by which HIV-1 activates pDCs, particularly the relevant immunostimulatory factors or signaling pathways. A possibility that HIV-1 might be detected through TLRs emerged from studies demonstrating that viral RNA or DNA can be potent activators of murine pDCs through ligation of TLR7 and -8 or TLR9, respectively. Murine pDCs produce IFN- $\alpha$ in response to the single-stranded RNA (ssRNA) viruses, influenza virus, and vesicular stomatitis virus (VSV) (22) without the requirement of viral replication; to ssRNA purified from influenza virus (23); and to RNA40 (a synthetic $[\mathrm{G}+\mathrm{U}]$ rich short oligoribonucleotide $[\mathrm{ORN}]$ derived from the HIV-1 U5 region) (24) via a TLR7-dependent pathway. HSV-1 

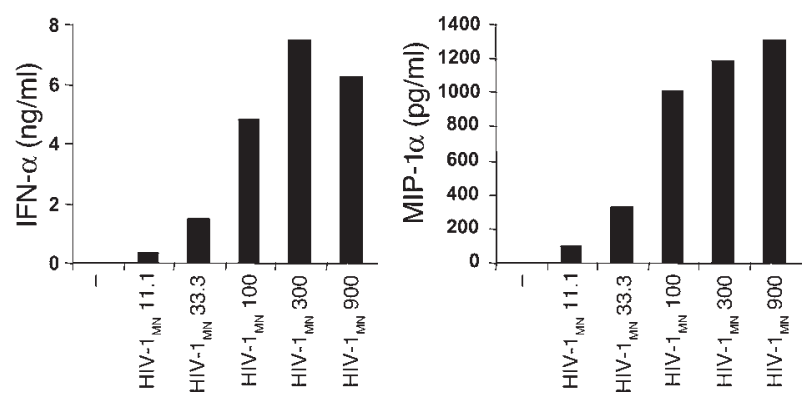

Figure 1

pDC activation in response to HIV-1. BDCA-4+ $4^{+}$DCs were cultured in the presence of various doses of HIV-1 $1_{\mathrm{MN}}(\mathrm{ng} \mathrm{p} 24 \mathrm{CA} / \mathrm{ml})$. Supernatants were collected after 15 hours and assessed for the presence of IFN- $\alpha$ $(\mathrm{ng} / \mathrm{ml})$ and MIP- $1 \alpha(\mathrm{pg} / \mathrm{ml})$ by ELISA.

$(25,26), \mathrm{HSV}-2$, and DNA purified from HSV-2 (27), as well as murine CMV (28) activate murine pDCs through TLR9. Baculovirus and baculoviral DNA have also been shown to stimulate the TLR9 signaling pathway (29). Furthermore, Heil et al. have shown that RNA40 activates human pDCs, and genetic complementation studies indicate that human TLR8 and not human TLR7 mediates its recognition (24). Significantly, entry into endosomes is required, as indicated by the need to formulate viral or synthetic ORNs with liposomes or cationic lipids $(23,24)$. However, human pDCs also detect ssRNA viruses (respiratory syncytial virus, Sendai virus), which directly enter host cells via fusion at the plasma membrane, in a TLR7/8- or TLR9-independent manner (30). Moreover, murine MDCs produce IFN- $\alpha$ in response to influenza virus (31) and mature in response to Sendai virus (32) in a replication-dependent manner and in the absence of TLR7/8 or TLR9 signaling.

Formal evidence that HIV-1 stimulates human pDCs through TLRs or after direct entry into the cytoplasm via fusion is lacking, however. Human pDCs do not express TLR8, indicating that HIV-1 must stimulate pDCs through another pathway. Furthermore, while both $\mathrm{pDCs}$ and MDCs produce inflammatory cytokines in response to RNA40 (IFN- $\alpha$ and IL-12p40, IL-6, and TNF- $\alpha$, respectively), only pDCs, but not MDCs, are activated in response to HIV-1 (21). It is also not known whether full-length genomic HIV-1 RNA is equally active as RNA40, nor whether HIV-1 RNA is the only stimulus from whole viral particles that activates $\mathrm{pDCs}$. As retrotranscription can occur within cell-free HIV-1 virions (33), it is possible that HIV-1 DNA within viral particles could activate PDCs through TLR9 and fail to stimulate MDCs, which lack this receptor. Finally, a role played by interactions between viral envelope glycoproteins from Newcastle disease virus, HSV-1, CMV, and HIV-1 and components of the plasma membrane has been demonstrated in the induction of the type I IFN response (34-38). In human pDCs, HIV-1-induced IFN- $\alpha$ is inhibited with neutralizing anti-CD4 antibodies (39), implicating a role for viral envelope glycoprotein-CD4 contact in pDC activation. Along those lines, we observed that envelope-deficient HIV-1 fails to elicit IFN- $\alpha$ production (21). Whether envelopereceptor interactions trigger signaling and direct activation of $\mathrm{pDCs}$ or induce receptor-mediated uptake and/or facilitate fusion to route HIV-1 nucleic acids to the appropriate TLR-expressing compartments also remains to be established.

To address these issues, we examined the role of viral envelopereceptor(s) engagement and the contribution of viral nucleic acidTLR interactions in mediating IFN- $\alpha$ production by human $\mathrm{pDCs}$ in response to HIV-1. We found that binding of envelope to CD4, leading to receptor-mediated endocytosis, as well as the presence of HIV-1 nucleic acids are required for pDC activation. Fusion is not involved in the detection of HIV-1 by pDCs. Viral RNA stimulates pDCs primarily through TLR7, whereas triggering by early DNA transcripts does not appear to be critical. These findings are important for understanding the pathogenesis of HIV infection. Exploiting this natural adjuvant activity of HIV-1 RNA might be useful in the development of vaccines or immunotherapies for the prevention of HIV infection or development of AIDS.

\section{Results}

Binding of gp160 to CD4 is necessary but not sufficient for HIV-1 to stimulate pDCs. HIV-1 enters cells by direct fusion with the plasma membrane or through receptor-mediated endocytosis. Uptake via nonspecific endocytosis is considered to be less significant. Direct fusion of virions with the plasma membrane occurs following a series of interactions between the trimers of the heterodimeric envelope glycoprotein gp $120^{\mathrm{SU}} / \mathrm{gp} 41^{\mathrm{TM}}$ on the virions, the cell-surface receptor CD4, and a coreceptor, usually CXCR4 or CCR5, depending on the strain (X4 or R5 tropic). Fusion is $\mathrm{pH}$ independent and facilitates the insertion of HIV-1 cores into the cytoplasm, which, depending upon the cell type, may lead to productive infection. In contrast, endocytosis can result in inactivation and concomitant degradation of virions within acidified endolysosomes and, in most cells, in nonproductive infection. In the case of MDCs, vesicular uptake of HIV-1 primarily occurs via CD4 (which acts as an endocytic receptor) and through CLRs such
A

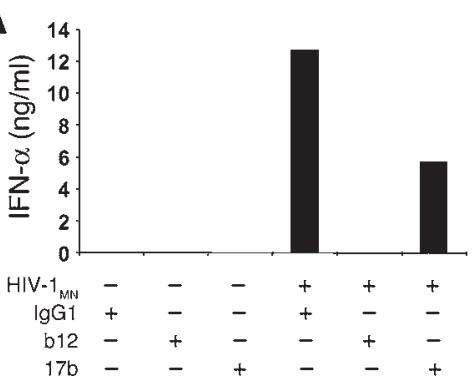

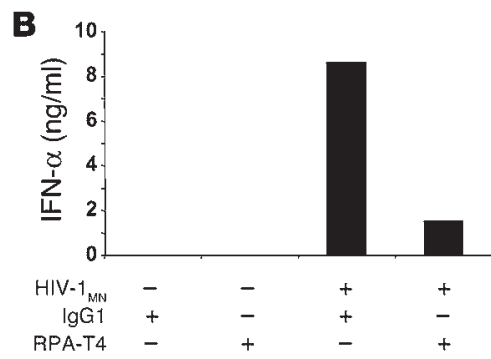

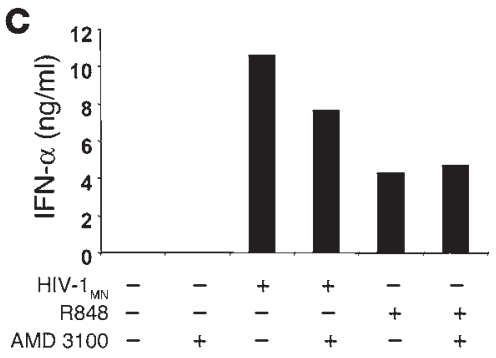

Figure 2

Inhibition of binding. BDCA-4+ pDCs were cultured overnight in the presence of HIV-1 $1_{\mathrm{MN}}$ or R848 and a neutralizing anti-gp120 mAb, b12 or $17 \mathrm{~b}$, versus an irrelevant human IgG1 (A); a neutralizing anti-CD4 antibody versus an irrelevant murine IgG1 (B); or AMD 3100 (C). The presence of IFN- $\alpha(\mathrm{ng} / \mathrm{ml})$ in the supernatants was assessed by ELISA. 
as DC-SIGN, which promotes infection in both a cis and a trans manner. Far less is known about how pDCs interact with HIV-1. pDCs express CD4, CXCR4, and CCR5 (39-41) but not DC-specific ICAM-3-grabbing nonintegrin (DC-SIGN) (42). They are also less efficient at internalizing particulate antigens compared with MDCs (40, 43-45). Nevertheless, pDCs undergo profound activation in response to HIV-1 $(21,39)$, including secretion of IFN- $\alpha$ and CCL3 (MIP-1 $\alpha$ ), which may protect PDCs and surrounding cells from HIV infection (Figure 1). RANTES production was low or not detectable (data not shown). As indicated by dose-response experiments, we used $300 \mathrm{ng}$ p $24^{\mathrm{CA}} \mathrm{Eq} / \mathrm{ml}$ of the $\mathrm{MN}$ strain of HIV-1 (HIV-1 $\left.1_{\mathrm{MN}}\right)$ as an optimal stimulus of pDC activation and relied on IFN- $\alpha$ and TNF- $\alpha$ secretion and CD83 upregulation as a measure of $\mathrm{pDC}$ activation, with IFN- $\alpha$ production being the most sensitive marker (Figure 1).

To evaluate the role of envelope-pDC interactions in initiating pDC activation, we previously demonstrated that envelope-deficient HIV-1 fails to induce survival and maturation of pDCs or to elicit IFN- $\alpha$ production (21). We confirmed the critical role played by the viral envelope glycoprotein by using neutralizing anti-HIV-1 antibodies. When pDCs were cultured in the presence of HIV- $1_{\mathrm{MN}}$ and either b12, a human neutralizing anti-gp120 mAb, or 17b, a human neutralizing anti-gp $120 \mathrm{mAb}$ that binds to an epitope induced by binding of gp 120 to CD4, IFN- $\alpha$ production was inhibited, with b12 being more powerful than $17 \mathrm{~b}$ (Figure $2 \mathrm{~A}$ ). No effect was observed when a human IgG1 of irrelevant specificity was used. We next characterized the receptors utilized by HIV-1 to bind and gain entry into pDCs. A mouse neutralizing anti-human CD4 antibody, but not an irrelevant mouse IgG1, substantially decreased the capacity of $\mathrm{pDCs}$ to secrete IFN- $\alpha$ in response to HIV- $1_{\mathrm{MN}}$ (Figure $2 \mathrm{~B}$ ), in addition to MIP-1 $\alpha$ (data not shown).

The involvement of the coreceptor CXCR4 was studied using bicyclam AMD 3100, a synthetic antagonist of CXCR4 (46). Only a slight inhibition of $\mathrm{HIV}-1_{\mathrm{MN}}$ (X4 tropic) mediated IFN- $\alpha$ production was observed with a high dose of AMD 3100 (Figure 2C). As expected, the immunostimulatory effects of R848, a CXCR4-independent synthetic agonist of TLR7 and TLR8 used as a control stimulus, were not influenced by AMD 3100.

To test whether non-virion-associated HIV-1 envelope glycoprotein would mimic the effects induced by the whole viral particles, we exposed $\mathrm{pDCs}$ to a high dose of recombinant oligomeric HIV-1 $1_{\text {IIIB }}$ gp160 $(10 \mu \mathrm{g} / \mathrm{ml})(47)$. We estimate that this dose represents a molar excess of between 5 and 6 logs over the amount of virion-associated envelope glycoprotein used in most experiments. In contrast to HIV-1 $1_{\mathrm{MN}}$, recombinant gp160 did not activate $\mathrm{pDCs}$ (data not shown). Together, our results imply that binding of HIV envelope glycoprotein to CD4 is necessary but not sufficient for HIV-1 to stimulate pDCs.

Endocytosis but not fusion of HIV-1 is required for $\mathrm{pDC}$ activation. In order to discriminate between the requirement of fusion with the plasma membrane and/or endocytosis for pDCs to detect HIV, we used C34, a peptide that inhibits the post-CD4 binding conformational changes in the transmembrane envelope glycoprotein gp41 required for membrane fusion (46). In addition, we tested several inhibitors that block the uptake of particular matter, including viruses. Dimethyl amiloride (DMA) inhibits ion channels and blocks membrane ruffling and subsequent macropinocytosis. Cytochalasin D (CCD) disrupts the cytoskeleton by inhibiting actin polymerization and thus blocks the endocytotic trafficking, including clathrin-mediated entry (48). Finally, chlorpromazine blocks clathrin-coated pit-mediated endocytosis (49).

Although C34 did not affect the increase in TNF- $\alpha$ production or CD83 expression stimulated by HIV- $1_{\mathrm{MN}}$, it slightly increased IFN- $\alpha$ production (Figure $3 \mathrm{~A}$ ). On the other hand, DMA, CCD, and chlorpromazine fully inhibited IFN- $\alpha$ secretion (Figure 3, B and $\mathrm{C}$ ), suggesting that endocytosis is required for HIV-1 to stimulate $\mathrm{pDCs}$. Although less dramatic, inhibition of IFN- $\alpha$ production by DMA and CCD was also observed in response to R848, consistent with previous observations that activation of TLR7, which is located intracellularly and not on the cell surface, occurs within
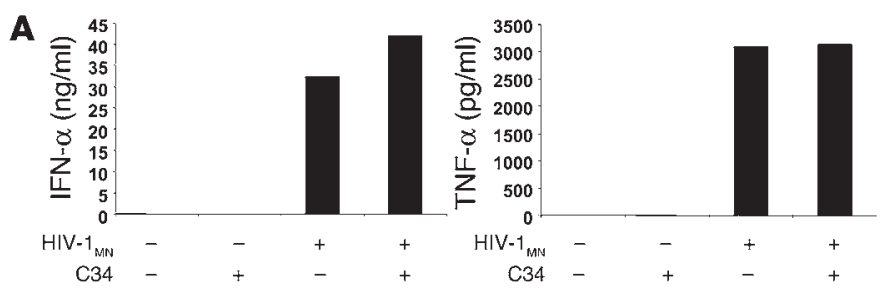

B

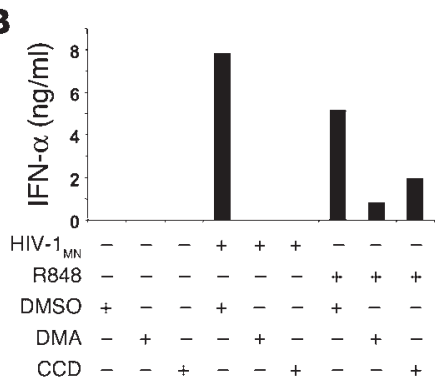

c

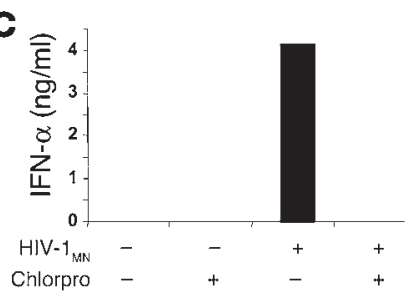

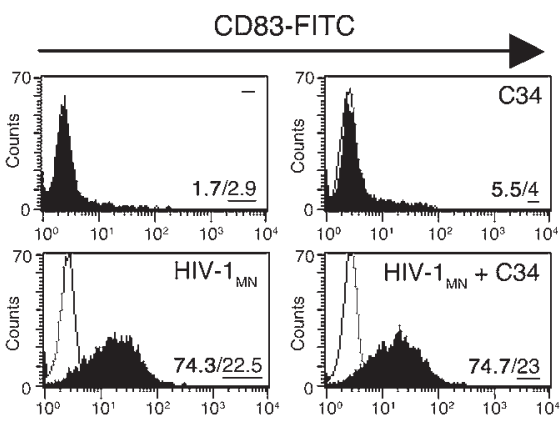

Figure 3

Inhibition of fusion with plasma membrane and endocytosis. (A) Flow cytometry-sorted pDCs were incubated overnight in the presence of HIV$1_{\mathrm{MN}}$ and C34. BDCA-4+ $\mathrm{pDCs}$ were cultured for 15 hours with HIV-1 ${ }_{\mathrm{MN}}$ and DMA, CCD, or DMSO (B) and chloropromazine (Chlorpro) (C). As a read-out, IFN- $\alpha(\mathrm{ng} / \mathrm{ml})$ and TNF- $\alpha(\mathrm{pg} / \mathrm{ml})$ secretion and CD83 expression were measured by ELISA and flow cytometry, respectively. The percentage of positive cells is indicated in bold and the mean of fluorescence intensity underlined. 

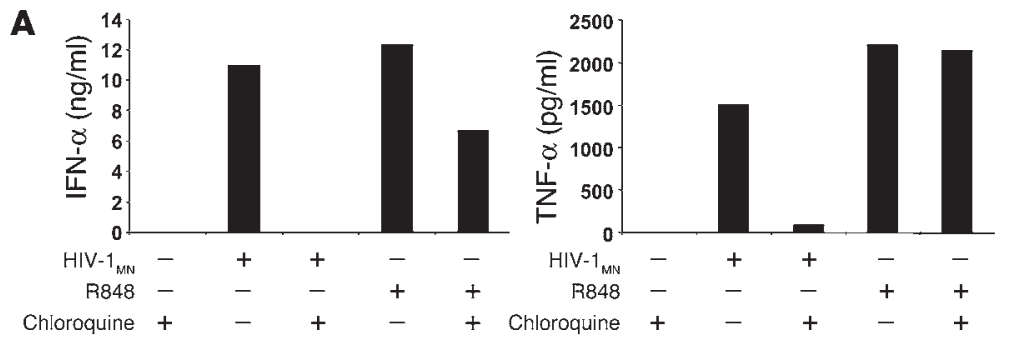

B
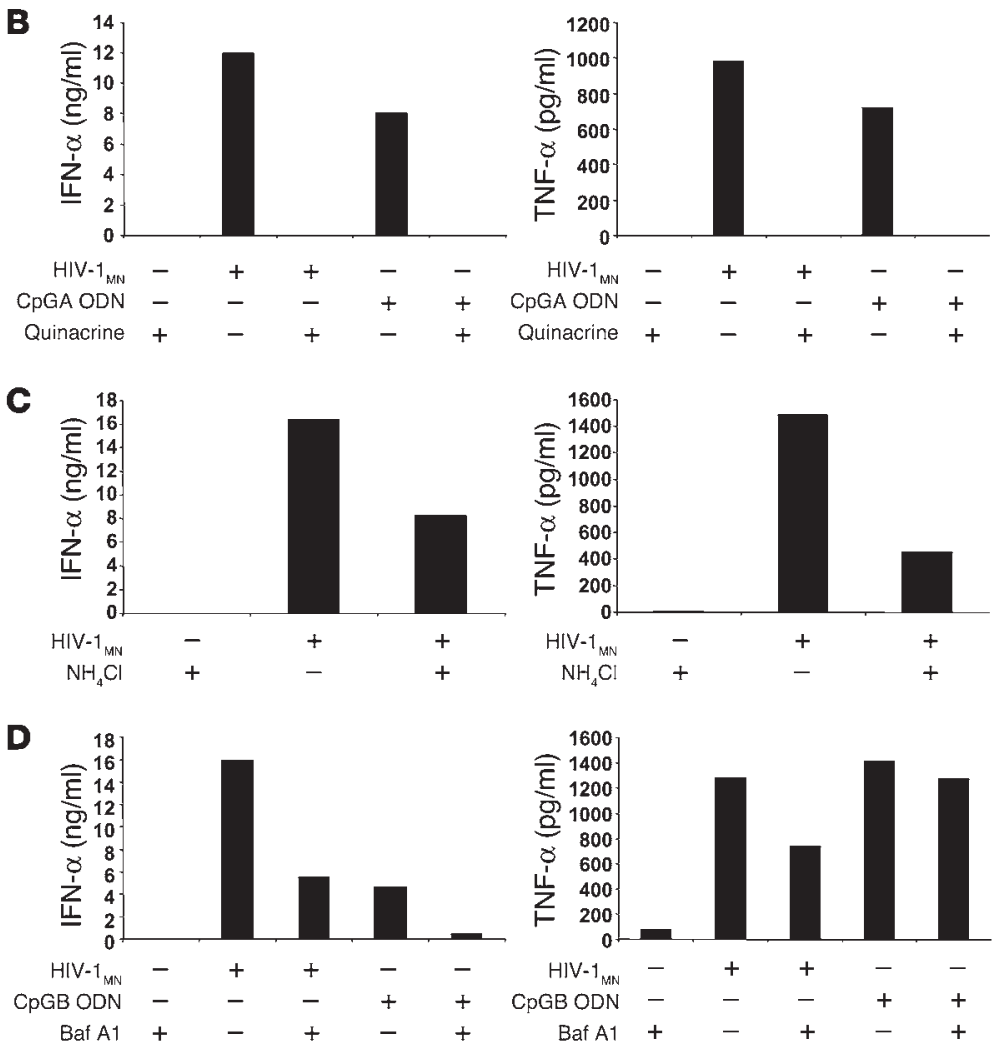

endosomes $(50,51)$. The effects observed were not attributable to nonspecific toxicity of inhibitors, based on trypan blue exclusion (data not shown).

We next examined whether acidification/maturation of the endosomes is necessary for HIV-1 to activate pDCs using chloroquine and quinacrine, 2 lysosomotropic weak bases that diffuse across membranes in a concentration-dependent manner, become protonated and thereby neutralize the acidic environment of endocytic vesicles. Chloroquine and quinacrine treatment caused full inhibition of IFN- $\alpha$ and TNF- $\alpha$ secretion induced by HIV-1 (Figure 4, A and B). Chloroquine treatment also resulted in inhibition of MIP-1 $\alpha$ secretion (data not shown). As expected, chloroquine and quinacrine inhibited the IFN- $\alpha$ production induced by $\mathrm{R} 848$ and CpG-containing oligodeoxyribonucleotides (CpG ODNs, synthetic ligands of TLR9) (Figure 4, A and B). Since their inhibitory effects might be mediated not by interfering with the acidification of vesicles (52), but by blocking binding of ODNs to TLR9 (53), we also tested ammonium chloride $\left(\mathrm{NH}_{4} \mathrm{Cl}\right)$ (Figure $3 \mathrm{C}$ ), another weak base unrelated to chloroquine, and bafilomycin A1 (Baf A1), a prototype compound from another class of endosomal acidification inhibitors that acts on vacuolar $\mathrm{H}^{+}$-ATPases (Figure 4D). Although

\section{Figure 4}

Inhibition of endosomal acidification/maturation. pDCs were enriched by BDCA-4 positive selection and cultured for 15 hours with HIV-1 $1_{\mathrm{MN}}$. The inhibitory effects of chloroquine $(\mathbf{A})$, quinacrine $(B), \mathrm{NH}_{4} \mathrm{Cl}(\mathbf{C})$ and Baf $\mathrm{A} 1$ (D) were assessed. IFN- $\alpha(\mathrm{ng} / \mathrm{ml})$ and TNF- $\alpha(\mathrm{pg} / \mathrm{ml})$ concentrations were determined by ELISA. As controls, pDCs were cultured with R848, CpGA or CpGB ODNs.

less effective than chloroquine and quinacrine, both $\mathrm{NH}_{4} \mathrm{Cl}$ and Baf A1 inhibited HIV-1-induced IFN- $\alpha$ and TNF- $\alpha$ production. As expected, Baf A1 inhibited the CPG ODN-mediated IFN- $\alpha$ secretion by pDCs. Notably, Baf A1 and chloroquine did not inhibit TNF- $\alpha$ production in response to $\mathrm{CPGB}$ and $\mathrm{R} 848$, respectively (Figure 4A). It has been suggested that $\mathrm{pH}$-sensitive endosomal TLR7 and TLR9 signaling is critical for activation of the MyD88/interferon regulatory factor 7 pathway and thereby IFN- $\alpha$ secretion, but it may not affect the NF- $\kappa$ B pathway, responsible for TNF- $\alpha$ induction (54). In conclusion, our findings suggest that endocytosis of HIV-1, and subsequent acidification of endosomes, rather than direct fusion of virions at the cell membrane, is the entry pathway required for pDC activation. However, its relevance for productive infection within these APCs is unknown.

$H I V-1$ RNA is responsible for the stimulation of $p D C s$. We next sought to identify the element from HIV-1 viral particles that activates $\mathrm{pDCs}$. To test the involvement of viral nucleic acids, we cultured pDCs with recombinant virions profoundly deficient in viral RNA packaging. Because nucleocapsid (NC) is critically involved in packaging of retroviral genomic RNA, the introduction of site-directed mutations in which all 6 cysteine residues of the conserved zinc finger structures of HIV-1 NC are replaced with serine results in a virus that forms virions virtually devoid of packaged viral RNA (55). An analysis of the HIV-1 RNA and DNA contents of the virus preparations revealed that, when normalized for equivalent levels of $\mathrm{p} 24^{\mathrm{CA}}$, the wild-type virus HIV- $1_{\text {NL4-3 }}$ (X4 tropic) contained 650 times more RNA copies and 143 times more DNA copies than the mutant virus NC SSHS/ SSHS HIV-1 $1_{\text {NL4-3 }}(\mathrm{X} 4$ tropic). This HIV DNA consists of HIV-1 sequences present in the plasmid DNA used to transfect $293 \mathrm{~T}$ cells that remained in the virus preparation even after DNase treatment of the recombinant HIV-1-containing supernatants, and/or of early retrotranscripts generated within the particles. Exposure of pDCs to the mutant NC SSHS/SSHS HIV- $1_{\mathrm{NL} 4-3}$ virions did not promote their survival (data not shown), induce the secretion of IFN- $\alpha$ or TNF- $\alpha$, or upregulate CD83 expression, in striking contrast to results obtained with the wild-type HIV-1 $1_{\text {NL4-3 }}$ virions (Figure $5 \mathrm{~A}$ ). The wild-type HIV-1 $1_{\mathrm{NL} 4-3}$ appeared to be less potent than $\mathrm{HIV}-1_{\mathrm{MN}}$, an outcome probably related to the method of production (transfection and ultracentrifugation of supernatants for HIV-1 $1_{\mathrm{NL} 4-3}$ versus infection and sucrose gradient ultracentrifugation for HIV-1 $1_{\mathrm{MN}}$ ), to the cells from which viruses are produced (293T cells vs. CEMX174 [T1] cells, respectively), as well as to the relative amount of viral nucleic acids (HIV- $1_{\mathrm{MN}}$ contained 0.6 times less RNA copies and 2 times more DNA copies than $\left.\mathrm{HIV}-1_{\mathrm{NL} 4-3}\right)$. In any case, our results confirmed that interactions 

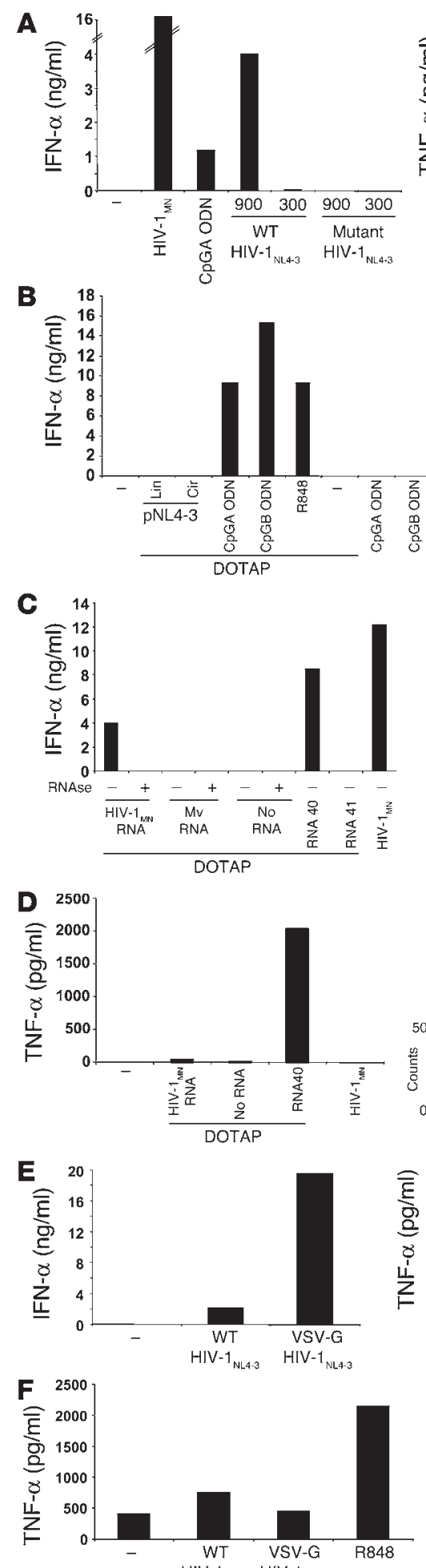

Figure 5

HIV RNA stimulates pDCs but not MDCs. (A) Flow cytometry-sorted pDCs were exposed overnight to recombinant wild-type or mutant NC SSHS/ SSHS HIV-1 $1_{\mathrm{NL} 4-3}$ at the doses of 900 or $300 \mathrm{ng} \mathrm{p} 24 \mathrm{CA} \mathrm{Eq} / \mathrm{ml}$. As controls, pDCs were cultured with CpGA ODN or HIV-1 $1_{\mathrm{MN}}$. (B) BDCA-4+ cells were

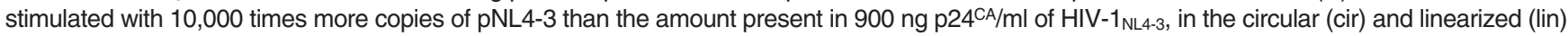
forms and after formulation with DOTAP. Low doses of CpGA and CpGB ODNs (1 $\mu \mathrm{g} / \mathrm{ml})$ and R848 (1 $\mu \mathrm{M})$ were used as controls. Flow cytometry-sorted blood pDCs (C) and MDCs (D) were treated overnight with HIV-1 MN RNA, microvesicle-derived RNA (Mv RNA), or with RNA40 and RNA41 mixed with DOTAP as controls. HIV-1 $1_{\mathrm{MN}}$ and Mv RNA were preincubated with RNase prior to formulation with DOTAP. Flow cytometry-sorted pDCs (E) and

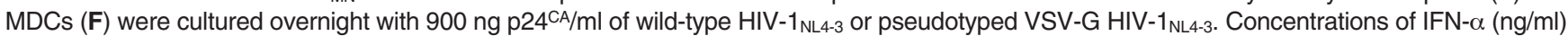
produced by $\mathrm{pDC}$ and TNF- $\alpha(\mathrm{pg} / \mathrm{ml})$ produced by $\mathrm{pDC}$ and MDCs were determined by ELISA. CD83 expression was measured by flow cytometry (the percentage of positive cells is indicated in bold and the mean of fluorescence intensity underlined). 
Table 1

Characterization of some inhibitors of TLR7

\begin{tabular}{lcrcccc} 
Stimulus & \multicolumn{5}{c}{ Competitor } \\
& None & $\mathbf{2 0 8 8}$ ODN & $($ TTAGGG) $\mathbf{~ O D N ~}$ & GpCB ODN & CpGB ODN & $\mathbf{m}^{\mathbf{1 , 7} \mathbf{0}^{8} \mathbf{G u}}$ \\
None & $1.00 \pm 0.22$ & $0.98 \pm 0.15$ & $1.03 \pm 0.1$ & $0.94 \pm 0.16$ & $0.93 \pm 0.08$ & $0.94 \pm 0.04$ \\
R848 & $19.34 \pm 1.2$ & $15.68 \pm 1.94$ & $6.54 \pm 0.5$ & $4.16 \pm 0.56$ & $14.59 \pm 1.2$ & $13.65 \pm 1.3$
\end{tabular}

HEK293 cells expressing hTLR7 and a NF-KB-luciferase reporter gene were stimulated with R848 in competition with 2088, (TTAGGG) 4 , GpCB, and CpGB ODNs and $\mathrm{m}^{1,7} \mathrm{O}^{8} \mathrm{Guo}$. Cells were lysed and assayed for luciferase gene activity. Data are expressed as fold increase in luciferase activity compared with unstimulated cells \pm SD.

CpG types A and C ODN are essential $(56,57)$. It is presumed that these factors underlie the basis for the self-assembly and the formation of optimally stimulating nanoparticles. Contrary to bacteria and to some viruses (i.e., HSV and CMV), the frequency of CpG motifs within HIV-1 DNA is low (58), in further support of our contention that HIV-1-associated DNA is unlikely to be the major factor stimulating IFN- $\alpha$ production.

Finally, in contrast to pDCs, we observed that RNA40, but not HIV-1 RNA, when

between HIV-1 envelope and pDCs are required but not sufficient for promotion of survival of $\mathrm{pDCs}$, induction of cytokine production, and upregulation of CD83 expression and demonstrated that HIV-1 nucleic acids are the main viral stimulus for pDCs.

To differentiate between nucleic acids, $\mathrm{pDCs}$ were cultured in the presence of plasmid DNA encoding HIV-1 or purified HIV-1 RNA. To date, it has been demonstrated that purified influenza virus RNA delivered within liposomes and purified HSV-2 DNA activate murine $\mathrm{pDCs}$ via TLR7 and TLR9, respectively. However they are 1,300 and 600 times less potent, respectively, in inducing IFN- $\alpha$ than RNA or DNA naturally packaged within viral particles (23, 27). When pDCs were exposed to plasmid DNA encoding HIV-1 $1_{\mathrm{NL} 4-3}$ (pNL4-3), circular or linear, and formulated in cationic lipids ( $\mathrm{N}-[1-$ (2,3-dioleoyloxy)propyl]-N,N,N-trimethylammonium methyl-sulfate [DOTAP]), they did not undergo full activation (i.e., they failed to induce IFN- $\alpha$ or to upregulate CD83), even when $\mathrm{pDCs}$ were treated with 10,000 times more copies of DNA than the amount present in $900 \mathrm{ng} \mathrm{p} 24^{\mathrm{CA}} / \mathrm{ml}$ of $\mathrm{HIV}-1_{\mathrm{NL} 4-3}$ (Figure $5 \mathrm{~B}$ ). When mixed with DOTAP, CpGA and CpGB ODNs exerted superior immunostimulatory activity, although R848-mediated effects were not enhanced, demonstrating the efficiency of the DOTAP delivery system (Figure 5B). In conclusion, the inability of linear pNL4-3 DNA to mimic $\mathrm{HIV}-1_{\mathrm{NL} 4-3}$ virions indicates that HIV-1 DNA is unlikely to be responsible for the observed stimulation of pDCs.

In contrast to viral DNA, and similarly to RNA40, when pDCs were exposed to $10 \mu \mathrm{g} / \mathrm{ml}$ of purified HIV-1 RNA preincubated with DOTAP, they released IFN- $\alpha$ and TNF- $\alpha$ and also upregulated CD83 (Figure $5 \mathrm{C}$ ). Ten micrograms/ml of purified HIV- $1_{\mathrm{MN}}$ RNA formulated with DOTAP (which corresponds to 2,666 times more copies of RNA than the amount present in $300 \mathrm{ng} \mathrm{p} 24 \mathrm{CA} / \mathrm{ml}$ of HIV- $1_{\text {MN }}$, since the mass ratio of p24 to RNA in HIV-1 is 8 ) was less stimulatory than $300 \mathrm{ng} \mathrm{p} 24^{\mathrm{CA}} / \mathrm{ml}$ of $\mathrm{HIV}-1_{\mathrm{MN}}$. RNase treatment inhibited the immunostimulatory effect (Figure 5C). Notably, RNA obtained from control microvesicles prepared from uninfected cells matched to those used to produce virions was ineffective at activating pDCs (Figure 5C), confirming the viral specificity of the $\mathrm{pDCs}$ ' activation. Together, our results suggest that HIV-1 genomic RNA, rather than DNA, is responsible for activating pDCs. It is worth noting that, for the induction of IFN- $\alpha$ through the TLR9/MyD88-dependent pathway, both the frequency of CPG motifs and the presence of the canonical palindromic structure present in formulated with DOTAP, stimulated MDCs to secrete TNF- $\alpha$ and to upregulate CD83 expression (Figure 5D). To further assess the nature of the differential responsiveness between $\mathrm{pDCs}$ and MDCs toward HIV-1 RNA, we cultured both subsets with pseudotyped VSV-G HIV- $1_{\mathrm{NL} 4-3}$ endocytosed in a CD4- and a coreceptor-independent manner (59). The pDC response to pseudotyped VSV-G HIV-1 $1_{\text {NL4-3 }}$ was largely higher than the one induced by wild-type HIV- $1_{\text {NL4-3 }}$ (Figure $5 \mathrm{E}$ ), whereas the unresponsiveness of MDCs to HIV-1 and HIV-1 RNA was not overcome (Figure 5F). Our data suggest that the differences in response to HIV-1 between pDCs and MDCs have to do not only with differential mode of entry but perhaps also with the final subcellular location of the virus.

HIV-1 activates a TLR pathway in PDCs. Our final goal was to determine how HIV-1 signals in pDCs. We analyzed the contribution of the TLR-mediated signaling pathways, since TLR7 and TLR9 expressed by human $\mathrm{pDCs}$ are involved in recognition of viruses and are responsible for IFN- $\alpha$ production. Moreover, they signal in endocytic compartments $(60,61)$, and their signaling is dependent on endosomal acidification $(50,51)$.

We made use of a set of TLR inhibitors that potentially act as specific TLR7 and TLR9 antagonists or partial agonists. Loxoribine is a synthetic ligand of TLR7, and nonstimulatory analogs, including $\mathrm{m}^{1,7} \mathrm{O}^{8} \mathrm{Guo}$, can inhibit loxoribine-mediated promitotic and adjuvant effects on murine cells (62). Inhibitory TLR9 agonists have been studied more extensively. Nonstimulatory ODNs, including 2088 ODN derived from murine immunostimulatory $\mathrm{CpG}$ 2084 ODN by base replacement (63) and the (TTAGGG) 4 motif found in mammalian telomeres (64), have been shown to neutralize the immunostimulatory effects of murine CpG ODNs. They are often utilized to demonstrate a TLR9 dependence in murine systems $(27,28,65,66)$. Similarly, the control GpCB ODN (with an inverted CPG motif) binds human TLR9 but fails to activate NF-KB nuclear translocation in HEK 293 cells and inhibits TLR9 signaling induced by CPGB ODN (60).

\section{Table 2}

Characterization of some inhibitors of TLR9

\begin{tabular}{|c|c|c|c|c|c|c|}
\hline \multirow[t]{2}{*}{ Stimulus } & \multicolumn{6}{|c|}{ Competitor } \\
\hline & None & 2088 ODN & $(\text { TTAGGG) })_{4}$ ODN & GpCB ODN & R848 & $\mathrm{m}^{1,7} 0^{8} \mathrm{Guo}$ \\
\hline None & $1.00 \pm 0.24$ & $1.03 \pm 0.15$ & $1.13 \pm 0.00$ & $1.49 \pm 0.31$ & $0.99 \pm 0.01$ & $0.94 \pm 0.04$ \\
\hline CpGB ODN & $8.61 \pm 0.47$ & $1.33 \pm 0.37$ & $2.33 \pm 0.31$ & $5.43 \pm 0.62$ & $5.39 \pm 0.45$ & $4.29 \pm 0.18$ \\
\hline
\end{tabular}

HEK293 cells expressing human TLR9 and an NF-KB-luciferase reporter gene were stimulated with CpGB

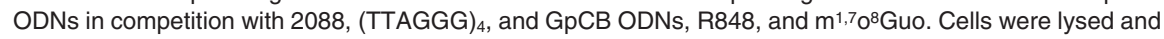
assayed for luciferase gene activity. Data are expressed as fold increase in luciferase activity compared with unstimulated cells \pm SD. 
We first evaluated the mechanisms of inhibition of these compounds, their specificity and degree of inhibitory effects. Competition assays with nonresponsive HEK 293 cells stably transfected with human TLR7 or TLR9 and a NF-KB-luciferase reporter gene were conducted. In the TLR7 system (Table 1), R848 activated NF- $\kappa$ B, whereas 2088, (TTAGGG) $)_{4}, \mathrm{GpCB}$, and CpGB ODNs and $\mathrm{m}^{1,7} \mathrm{O}^{8} \mathrm{Guo}$ did not. However, R848-induced TLR7-dependent NF- $\mathrm{KB}$ activation was significantly inhibited by GPCB and (TTAGGG) ${ }_{4} \mathrm{ODNs}$ and $\mathrm{m}^{1,7} \mathrm{O}^{8} \mathrm{Guo}$, in decreasing order. $\mathrm{CpGB}$ and 2088 ODNs were only mildly inhibitory. These data indicate that antagonists previously considered to be TLR9 specific also have the potential to inhibit TLR7 activation. Indeed, inhibition of TLR7 and TLR8 signaling by ODNs has been recently reported by Jurk and coworkers (67).

Conversely, in the TLR9 system (Table 2), only CpGB ODN was stimulatory, and 2088, (TTAGGG) 4 , and GPCB ODNs, R848, and $\mathrm{m}^{1,7} \mathrm{O}^{8} \mathrm{Guo}$ did not activate NF- $\mathrm{KB}$ through TLR9 at the concentrations used. However, they strongly inhibited CPGB ODN-induced TLR9-dependent NF- $\mathrm{KB}$ activation [in decreasing order: 2088 ODN, then (TTAGGG) ${ }_{4}$ ODN, then $\mathrm{m}^{1,7} \mathrm{O}^{8} \mathrm{Guo}$, then GPCB ODN, followed by R848]. It is interesting to note that even the TLR7 antagonist and agonist $\mathrm{m}^{1,7} \mathrm{o}^{8} \mathrm{Guo}$ and R848, respectively, were significantly inhibitory. These competition assays demonstrate that these inhibitory TLR ligands partially block both TLR7 and TLR9 and are not as specific as originally suggested. Actually, a recent paper describes that (TTAGGG) ${ }_{4}$ directly binds STAT1 and STAT4, preventing their phosphorylation (68). However, no direct binding to JNK or other NF-кB- and MAPK-related molecules was observed. Our study also provides striking evidence of complex relationships between TLR7 and TLR9.

Nevertheless, when tested for its effects on HIV-1induced $\mathrm{PDC}$ activation, $\mathrm{m}^{1,7} \mathrm{O}^{8} \mathrm{Guo}$ did not directly stimulate human pDCs, but it did reduce IFN- $\alpha$ and TNF- $\alpha$ secretion (Figure 6A), when a low dose of p $24^{\mathrm{CA}} \mathrm{Eq} / \mathrm{ml}$ of HIV- $1_{\mathrm{MN}}$ was used. These data suggest that inhibition of TLR7 can impair PDC activation by HIV-1, although the failure of $\mathrm{m}^{1,7} \mathrm{O}^{8} \mathrm{Guo}$ to inhibit R848-mediated $\mathrm{pDC}$ activation indicates that it is not a potent inhibitor when optimal doses of a TLR7 agonist are used.

Interestingly, 2088 (Figure 6B), (TTAGGG) ${ }_{4}$ (Figure 6C), and GpCB (Figure 6D) ODNs inhibited HIV-1-mediated effects. (TTAGGG) ${ }_{4}$ ODN had stronger inhibitory effects than 2088 ODN on IFN- $\alpha$ and TNF- $\alpha$ secretion (Figure 6, B and C). GpCB ODN fully inhibited IFN- $\alpha$ production and did not interfere with TNF- $\alpha$ secretion (Figure 6D). In addition, GpCB ODN alone exerted some immunostimulatory effects on $\mathrm{pDCs}$ (TNF- $\alpha$ production but not IFN- $\alpha$ ), although it did not activate NF- $\mathrm{B}$ in

\section{Figure 6}

Inhibition with some inhibitory TLR ligands. pDCs were stimulated overnight with 300 or $37.5 \mathrm{ng}$ p24 ${ }^{\mathrm{CA}} \mathrm{Eq} / \mathrm{ml}$ HIV- $1_{\text {MN }}$ and $m^{1,7} 0^{8}$ Guo (A), 2088 ODN (B), (TTAGGG) ${ }_{4}$ ODN (C), or GpCB ODN (D). As controls, CpGA and CpGB ODNs or R848 were used. IFN- $\alpha(\mathrm{ng} / \mathrm{ml})$ and TNF- $\alpha(\mathrm{pg} / \mathrm{ml})$ production were measured by ELISA. the 293 cells expressing TLR9. Our data are analogous to a recent study demonstrating that a non-CpG-containing immunostimulatory motif present in GPCB ODN can induce the upregulation of CD40, CD86, and MHC class I molecules on pDCs without stimulating IFN- $\alpha$ (69).

Based on our competition assays with 293 cells, and the inhibition of pDC stimulation following HIV-1 exposure by $\mathrm{m}^{1,7} \mathrm{o}^{8} \mathrm{Guo}$ and (TTAGGG) 4 , GpCB, and 2088 ODNs, our data suggest that TLR7 and/or TLR9 participate in the activation pathway, although their mode of action remain to be fully determined. We made several additional attempts to identify the TLR involved in $\mathrm{pDC}$ activation in response to HIV. Initially, we used genetic complementation and the TLR-transfected HEK 293 cells, as described in Tables 1 and 2. NF- $\mathrm{KB}$ activation was detected when HEK 293 cells expressing TLR7 were exposed to HIV-1 after pretreatment with lipofectamine, to overcome the entry requirement for $\mathrm{CD} 4$ and chemokine receptors (Figure 7A). In contrast, lipofectamine-facilitated HIV-1 induced substantially lower relative activation of TLR9-expressing HEK 293 cells, when compared with the positive control, CpGB (Figure 7B, note the $y$ axis). These data are certainly consistent with the idea

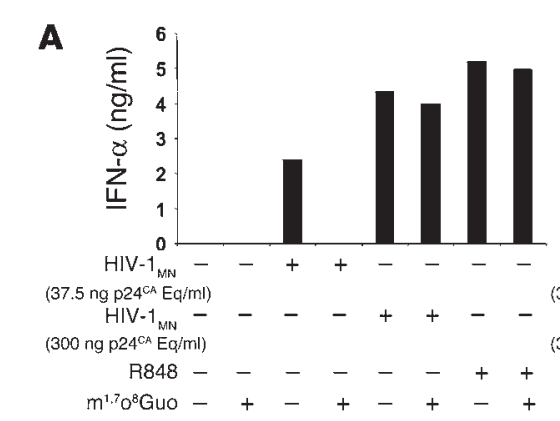

B
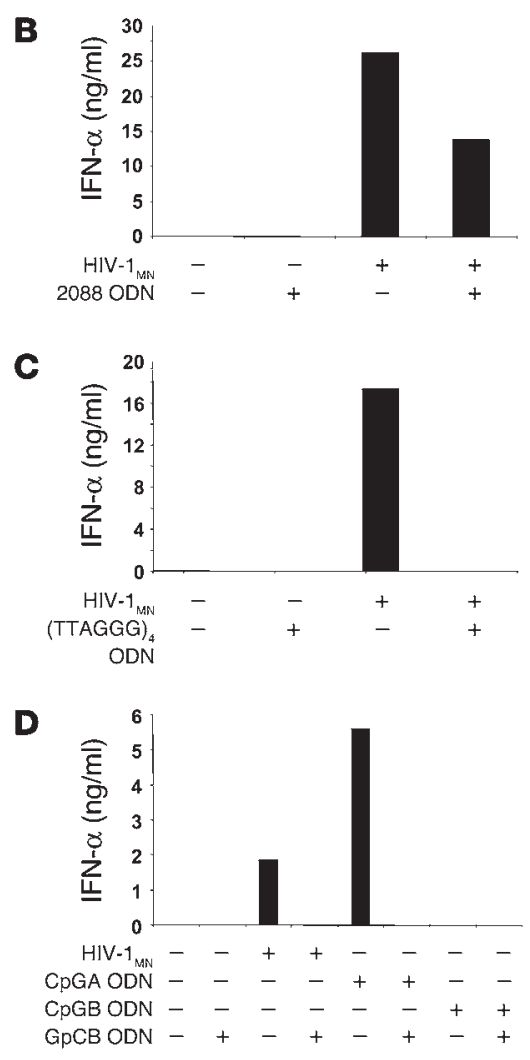
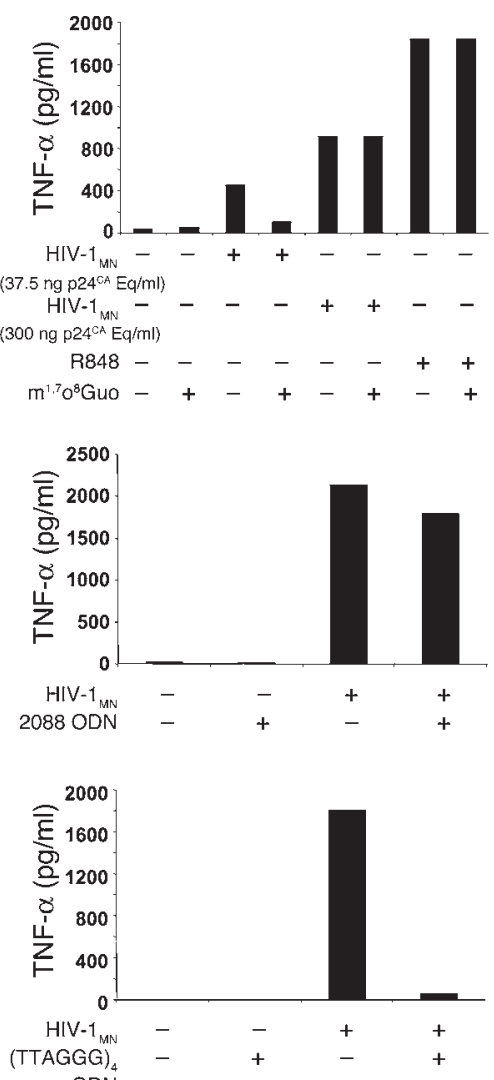

ODN

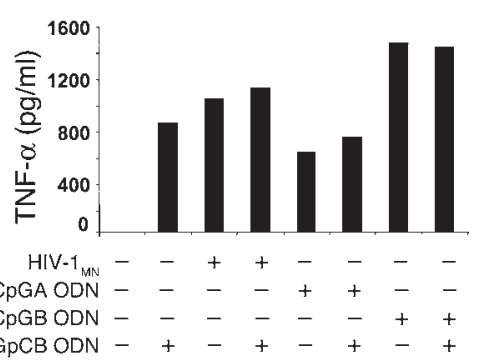



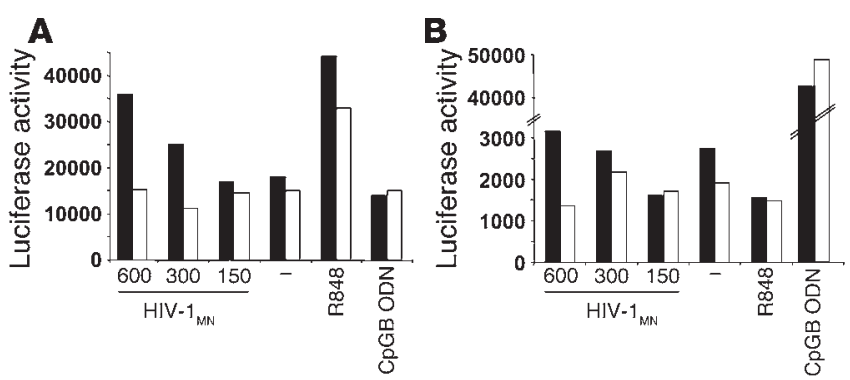

Figure 7

TLR7 is the likely target of HIV in pDCs. HEK 293 cells expressing human TLR7 (A) or human TLR9 (B) and an NF-кB-luciferase reporter gene were pretreated (black bars) or not (white bars) with lipofectamine and stimulated overnight with HIV-1 $1_{\mathrm{MN}}$ at doses of 600 , 300 , and $150 \mathrm{ng} \mathrm{p} 24^{\mathrm{CA}} \mathrm{Eq} / \mathrm{ml}$, R848, or CpGB ODN. Cells were lysed and assayed for luciferase gene activity. Data are expressed as luciferase activity in relative light units and are representative of 2 independent experiments.

that HIV-1 preferentially activates pDCs via viral RNA-TLR7 interactions following CD4-mediated endocytosis.

Subsequent studies testing the capacity of TLR7 ${ }^{-/}$or TLR9-/mice to respond to VSV glycoprotein-pseudotyped HIV-1 (as HIV-1 does not infect murine cells) were inconclusive in that cells from both mice showed evidence of low levels of activation (data not shown). These data were difficult to interpret, as HIV-1 RNA may not efficiently interact with murine TLRs or may utilize murine TLRs differently from human cells. It is known that TLR expression on DC subsets in mice differs from that in humans. Finally, we were not successful in blocking either TLR7 or TLR9 activity using specific siRNA constructs, as recently described (70). All told, our findings point to a requirement for an endocytic, TLRdependent pathway that leads to the activation of human pDCs by HIV-1 RNA. Further studies with better-characterized reagents will be necessary to determine whether activation also requires the contribution of multiple TLRs (e.g., TLR7 and TLR9).

\section{Discussion}

HIV-1 endocytosis by pDCs. Human DC subsets respond differently upon encountering HIV-1. While blood pDCs undergo a complex program of activation and differentiation $(21,39)$, MDCs fail to mature or produce proinflammatory cytokines such as IL-12 and instead induce $\mathrm{T}$ cell-dependent immunosuppression (71). Our studies have focused on the mechanism(s) by which HIV-1 activates pDCs from entry (72) to activation. Our results demonstrate that endocytosis is the primary mode of entry of HIV-1 for pDC activation and that this initial step is dependent upon interactions between viral envelope and CD4. Indeed, $\mathrm{pDCs}$ fail to undergo activation when exposed to envelope glycoprotein-deficient HIV-1 (21). In addition, pDC activation, and most particularly IFN- $\alpha$ production, is substantially inhibited in the presence of (a) blocking mAbs to gp120 (b12, 17b) and to CD4 and (b) inhibitors of endocytosis. Finally, pDC activation by HIV-1 does not involve fusion with plasma membrane. Fusion does not require $\mathrm{pH}$-dependent conformation changes of the viral envelope glycoprotein and therefore should be resistant to inhibition of endosomal acidification. Using an extensive panel of inhibitors, we demonstrated a requirement for endosomal acidification for HIV-1 to stimulate pDCs. Interestingly, blockade of HIV-1 fusion with C34 resulted in a slight increase in IFN- $\alpha$ production by pDCs. This is likely due to enhanced virion entry via the endocytic pathway, based on a compensatory relationship between fusion and endocytosis reported recently in $\mathrm{CD}^{+} \mathrm{T}$ cells (73). Fusion of HIV-1 virions likely occurs in parallel to endocytosis and may lead to productive infection of pDCs $(74,75)$; however, fusion and viral replication are not necessary for pDCs to detect the virus and undergo activation $(21,39)$.

As purified envelope glycoprotein gp160 failed to stimulate pDCs, we do not believe viral envelope glycoprotein-plasma membrane interactions directly trigger the type I IFN pathway, as postulated for other viruses and HIV-1. Instead, we consider that binding of viral envelope to $\mathrm{CD} 4$, and the consequent receptor-mediated endocytosis that is triggered, is required to shuttle virions and their nucleic acids into the appropriate compartment where TLRs are expressed.

HIV-1 genomic RNA activates pDCs through a TLR pathway. HIV-1 RNA rather than DNA retrotranscripts appears to be essential for activating $\mathrm{pDCs}$. Several lines of evidence support this conclusion. First, recombinant virions deficient in packaged viral RNA failed to trigger pDC activation. Second, purified HIV-1 RNA, and not control RNA from microvesicles, when complexed with DOTAP stimulated pDCs, whereas plasmid DNA encoding HIV-1 was ineffective.

While we demonstrated that HIV-1 RNA triggered a TLR pathway in pDCs by using inhibitory ligands, their "promiscuity" complicated the identification of which TLR (TLR7 or TLR9) was targeted by HIV-1 RNA and exposed a heretofore-unappreciated complexity in the relationship between TLR7 and TLR9 instead. The possibility remains, however remote, that HIV-1 RNA may signal through both TLR7 and TLR9. Likewise, CPG constructs may also rely on a contribution by TLR7 (54). Despite an exhaustive analysis using (a) stably transfected TLR7 or TLR9 HEK 293 cell lines, (b) cells from mice deficient in TLR7 or TLR9, and (c) the application of siRNAs to selectively knock down TLR expression, we could not conclusively identify TLR7 as the sole receptor for HIV-1 RNA, nor could we clearly exclude a role for TLR9. However, when considered together with studies that used TLR7-deficient mice to define the target for ssRNA viruses, purified ssRNA, and ORNs and studies that demonstrated that TLR9 needs a DNA-like structure rather than a RNA-like sugar conformation for optimal recognition (76), our data are most consistent with the concept that HIV-1 RNA primarily activates human pDCs via TLR7 and not TLR9.

Requirement for endocytic acidification. Endocytic acidification is critical for pDCs to detect several viruses, as well as synthetic agonists of TLR7 and TLR9. The molecular basis of this requirement remains to be defined. Presumably HIV-1 virions need to be degraded by $\mathrm{pH}$-dependent lipases and proteases to free their genomic RNA. In addition, it is possible that the endosomal acidic environment facilitates physical access of genomic RNA to its TLR targets once released from its envelope. Finally, endosomal maturation may be necessary for the recruitment and/or activation of the signaling machinery, as suggested by the sensitivity of MyD88 recruitment to Baf A1 in loxoribine-induced TLR7 signaling (51) and the translocation of TLR9 and MyD88 to the site of entry of CPG ODNs $(60,61)$.

Differential responses of $p D C s$ and MDCs to HIV-1. RNA40 formulated with DOTAP and influenza virus successfully activate both human MDCs and PDCs, presumably because they both share TLR7. In contrast, only pDCs are activated in response to HIV-1 and HIV-1 RNA. If HIV-1 RNA triggers both TLR7 and TLR9, then the differential responsiveness of $\mathrm{pDCs}$ and MDCs may reflect 
the set of TLRs they express. pDCs express TLR7 and TLR9 but not TLR8, and MDCs express TLR7 and TLR8 but not TLR9. One other possibility is that responses to HIV-1 could simply reflect differences in terms of TLR7 expression and function between the 2 subsets. Indeed, the intensity of the TLR7 mRNA expression has been reported to be lower in MDCs than in $\mathrm{pDCs}(2,3,5)$. In addition, TLR7 and TLR8 differ in specificity, sensitivity, and signaling $(50,51,77)$ and might interact together in MDCs. Nevertheless, one cannot completely rule out differential uptake pathways and, more importantly, subsequent subcellular localizations and duration of endosomal retention as pointed out recently $(54,78)$ in MDCs versus pDCs. In particular, sequestration of HIV-1 in DC-SIGN-expressing vesicles in MDCs might permit HIV-1 RNA to avoid encounter with TLR7, the DC-SIGN contribution being surmounted when RNA40 is targeted to TLR7 with DOTAP, but not by HIV RNA with DOTAP or VSV-G-pseudotyped HIV-1. In contrast, CLRs specifically expressed by pDCs could cooperate with TLR7 and TLR9. Further studies will be necessary to determine the nature of the differential response of MDCs and pDCs to HIV-1 and particularly the contribution of CLRs.

Pathophysiology of HIV-1 and vaccine development. Our studies emphasize the important role pDCs play in the pathophysiology of HIV-1 infection. As a result of HIV-1 activation, not only do pDCs produce antiviral type I IFNs, but by inducing the bystander maturation of MDCs (21), they might overcome the potentially suppressive effect HIV-1 may have on MDCs. A combination of agonists targeting TLR7 and TLR9 may provide an effective approach to maintaining DC functions in chronic HIV-1 infection. Alternatively, chemically treated HIV-1, which has the same activity as live virus on pDCs, would be a suitable and safe alternative if incorporated into a vaccine. The advantage of this approach is the concomitant delivery of antigens and TLR agonist. Indeed, when targeted to DCs, this form of virus induces a potent therapeutic immune response in humans (79).

\section{Methods}

$p D C$ purification. Leukocyte-enriched buffy coats were obtained from the New York Blood Center. PBMCs were separated by centrifugation on FicollHypaque (Amersham Pharmacia Biotech). pDCs were positively selected with anti-BDCA-4-conjugated magnetic microbeads over 2 LS Columns (Miltenyi Biotec). The purity of pDCs was analyzed by staining with antiBDCA-2-FITC (Miltenyi Biotec) and anti-CD123-PE (BD) mAbs and was within the range of $75-95 \%$. Data were systematically confirmed with flow cytometry-purified pDCs as previously described (21).

$H I V-1, H I V-1$ RNA, and DNA. Virions of HIV-1 $1_{\mathrm{MN}}$ (X4 tropic) were produced by infection from the HIV-1 CEMX174 (T1) cell line and purified by sucrose gradient ultracentrifugation after cells were removed by tangential flow filtration or by clarification as previously described (80-82). Samples were titrated for the presence of infectious virus using AA2CL.1 cells and HIV-1 p24 antigen capture kits (AIDS Vaccine Program, National Cancer Institute). Virions of wild type HIV-1 $1_{\mathrm{NL4}-3}$ (X4 tropic), pseudotyped VSV-G HIV- $1_{\mathrm{NL} 4-3}$, and mutant NC SSHS/SSHS HIV- $1_{\mathrm{NL4}-3}$ were produced by transfection of 293 T cells with pNL4-3 based on pUC19 (55), concentrated by ultracentrifugation, and treated with nucleases, which were inactivated and removed by addition of $50 \mathrm{mM}$ EDTA and centrifugation through $20 \%$ (vol/vol) sucrose. Quantification of p24 levels was performed using SYPRO Orange fluorescent protein stain of a SDS-PAGE gel (Invitrogen Corp.). HIV-1 RNA and DNA contents of the virus preparations were also determined using standard real-time RT-PCR and real-time PCR. pNL4-3 DNA was digested at a unique restriction site using SmaI (New England
Biolabs Inc.). Full-length genomic HIV-1 RNA was purified from HIV-1 $1_{\mathrm{MN}}$ virions (clone 4) and microvesicle-derived from uninfected CEMX174 cells according to previously published methods (83). Prior to formulation with DOTAP, RNA was digested by $200 \mathrm{U}$ RNase If/ $1 \mu \mathrm{g}$ of RNA (New England Biolabs Inc.) into mono-, di-, and trinucleotides.

Culture and stimulation of primary pDCs. Freshly isolated pDCs were cultured at $10^{6}$ cells $/ \mathrm{ml}$ in RPMI 1640 with $20 \mu \mathrm{g} / \mathrm{ml}$ gentamicin (Invitrogen Corp.) and $5 \%$ pooled human serum (Cellgro; Mediatech Inc.). Cells were incubated overnight with $300 \mathrm{ng}$ p $24^{\mathrm{CA}} \mathrm{Eq} / \mathrm{ml} \mathrm{HIV}-1_{\mathrm{MN}}$, corresponding to $400-1,200$ particles per cell; $10 \mu \mathrm{M}$ R848 (GLSynthesis Inc.); $2 \mu \mathrm{g} / \mathrm{ml} \mathrm{CpG} \mathrm{containing}$ ODN type A (D)/2216 (CpGA ODN, G*G*GGGACGATCGTC ${ }^{*} G^{*} G^{*} G^{*} G$ $\left.{ }^{*} \mathrm{G}^{*} \mathrm{G}\right) ; 2 \mu \mathrm{g} / \mathrm{ml}$ CpG ODN type B (K)/2006 (CpGB ODN, $\mathrm{T}^{*} \mathrm{C}^{*} \mathrm{G}^{*} \mathrm{~T}^{*} \mathrm{C}^{*} \mathrm{G}$ ${ }^{*} T^{*} T^{*} T^{*} T^{*} G^{*} T^{*}{ }^{*} G^{*} T^{*} T^{*} T^{*} T^{*} G^{*} T^{*}{ }^{*} G^{*} T^{*} T$ ), where CpG motifs are underlined and the asterisks indicate a phosphorothioate bond (Integrated DNA Technologies Inc.); $10 \mu \mathrm{g} / \mathrm{ml}$ RNA40 (ORN derived from HIV-1 U5 region nt $108-127, G *{ }^{*} C^{*} C^{*} G^{*} U^{*} C^{*} U^{*} G * U^{*} U * G * U^{*} G *{ }^{*} G * A * C * U$ $\left.{ }^{*} \mathrm{C}\right) ; 10 \mu \mathrm{g} / \mathrm{ml} \mathrm{RNA} 41$ as a negative control (U to A replacement in RNA40) (Dharmacon Inc.); or $10 \mu \mathrm{g} / \mathrm{ml}$ of HIV- $1_{\mathrm{MN}}$ RNA. ORNs, purified genomic viral RNA, and plasmid DNA were formulated with $12.5 \mu \mathrm{g} / \mathrm{ml}$ DOTAP Liposomal Transfection Reagent (Roche Diagnostics Corp.).

ELISA and flow cytometry. The presence of IFN- $\alpha$ (PBL Biomedical Laboratories), TNF- $\alpha$ (BD Biosciences - Pharmingen), and MIP- $1 \alpha$ (R\&D Systems) in pDC supernatants was evaluated by ELISA. Magnetically purified BDCA-4 ${ }^{+}$ pDCs were stained with FITC-conjugated mAb against CD83 (BD) and PE-conjugated $\mathrm{mAb}$ against CD123 (BD), whereas flow cytometry-sorted pDCs and MDCs were stained with FITC-conjugated mAb against CD83 (BD). Cells were fixed with PBS containing 4\% paraformaldehyde (SigmaAldrich) prior to acquisition. Fluorescence was analyzed by flow cytometry on a FACScalibur using CellQuest software (BD).

Binding and fusion inbibitors. pDCs were treated with 1 of the following HIV binding and fusion inhibitors and $300 \mathrm{ng} \mathrm{p} 24^{\mathrm{CA}} \mathrm{Eq} / \mathrm{ml} \mathrm{HIV}-1_{\mathrm{MN}}$ : b12 and $17 \mathrm{~b}$ $(5 \mu \mathrm{g} / \mathrm{ml}), 2$ human anti-gp120 mAbs (gift from D. Burton, Scripps Research Institute, San Diego, California, USA); a mouse neutralizing anti-human CD4 antibody $(1 \mu \mathrm{g} / \mathrm{ml})$ (RPA-T4; BD); bicyclam AMD $3100(5 \mu \mathrm{g} / \mathrm{ml})$ and C34 (50 nM) (NIH AIDS Research and Reference Reagent Program).

Endocytosis and endosomal maturation inhibitors. $\mathrm{pDCs}$ were cultured in the presence of $300 \mathrm{ng} \mathrm{p} 24^{\mathrm{CA}} \mathrm{Eq} / \mathrm{ml} \mathrm{HIV}-1_{\mathrm{MN}}$ and various endocytosis and endosomal maturation/acidification inhibitors: DMA $(50 \mu \mathrm{M})$; CCD (10 $\mu \mathrm{M})$; chlorpromazine $(6.25 \mu \mathrm{g} / \mathrm{ml})$; chloroquine $(5 \mu \mathrm{M})$; quinacrine $(5 \mu \mathrm{M})$; $\mathrm{NH}_{4} \mathrm{Cl}(1 \mathrm{mM})$; and Baf A1 (50 nM), all from Sigma-Aldrich except for chlorpromazine, which was from Elkins-Sinn Inc.

Luciferase assay. Stably transfected HEK 293 cells $\left(15 \times 10^{4}\right.$ cells/well $)$ expressing human TLR7 and TLR9 (gift from Coley Pharmaceutical Group Inc.), previously described, were stimulated overnight with R848 or CPGB ODN in competition with various inhibitory TLR ligands, lysed, and assayed for luciferase gene activity using a luciferase assay kit (Promega) and a luminometer (Wallac VICTOR ${ }^{3}$; PerkinElmer). In experiments examining the effects of HIV-1, $0.5 \mu \mathrm{l}$ of lipofectamine, suspended in $25 \mu \mathrm{l}$ of OPTIMEM (Invitrogen Corp.) for 10 minutes, was added to HEK 293 cells for 1.5 hours. HIV-1 was added for an additional hour. Then media was supplemented with FCS to a final concentration of $10 \%$ for overnight culture. Stimulation indices were calculated in reference to reporter gene activity of unstimulated cells.

Inhibitory TLR7 and TLR9 ligands. pDCs were cocultured with 300 or 37.5 ng p24CA equivalents/ml HIV- $1_{\mathrm{MN}}$ and $100 \mu \mathrm{M}$ of $\mathrm{m}^{1,7} \mathrm{o}^{8} \mathrm{Guo}$ (gift from Ribapharm) or $10 \mu \mathrm{g} / \mathrm{ml}$ of control GpC ODN type B (K)/2006 (GpCB ODN, $\left.T^{*} G^{*} C^{*} T^{*} G^{*} C^{*} T^{*} T^{*} T^{*} T^{*} G^{*} T^{*} G^{*} C^{*} T^{*} T^{*} T^{*} T^{*} G^{*} T^{*} G^{*} C^{*} T^{*} T\right), 2088$ ODN $\left(T^{*} C^{*} C^{*} T^{*} G^{*} G^{*} C^{*} G^{*} G^{*} G^{*} G^{*} A^{*} A^{*} G^{*} T\right.$ ), and (TTAGGG) ${ }_{4}$ ODN ( T* $\left.T^{*} A^{*} G^{*} G^{*} G^{*} T^{*} T^{*} A^{*} G^{*} G * G^{*} T^{*} T^{*} A^{*} G^{*} G^{*} G * T^{*} T^{*} A^{*} G * G * G\right)$ (all from Integrated DNA Technologies Inc.). 
Statistics. Data shown are representative of greater than or equal to 3 independent experiments. Two-tailed paired Student's $t$ test was used to determine statistical significance.

\section{Acknowledgments}

These studies were supported by grants AI44628 and AI55274 (to N. Bhardwaj) from the NIH and CA84512 (to N. Bhardwaj) and NO1-CO-124000 (to R.J. Gorelick and J.D. Lifson) from the National Cancer Institute, the Mary Kirkland Foundation, the Cancer Research Institute, and the Burroughs Wellcome Foundation (to N. Bhardwaj). N. Bhardwaj is a Doris Duke Distinguished Scientist and an Elizabeth Glaser Scientist. A.-S. Beignon was supported by La Fondation pour la Recherche Médicale and a grant from the Center for AIDS Research at the New York University School of Medicine. The New York University Sackler Institute provided support for K. McKenna. The authors would like to thank Svetlana Mazel and Tamara Shengelia (The Rockefeller University) for their expertise in sorting pDCs and MDCs as well as Jean-François Fonteneau (INSERM U463), Robert Tam (Ribapharm), Michael Goodman (formerly of R.W. Johnson Pharmaceutical Research Institute), Petar Lenert (University of Iowa), Arthur Krieg (Coley Pharmaceutical Group Inc.), Dan Littman (Skirball Institute of Biomolecular
Medicine), Yong Jun Liu (M.D. Anderson Cancer Center), Rongfu Wang (Baylor College of Medicine), Caetano Reis e Sousa (London Research Institute), Akiko Iwasaki (Yale University School of Medicine) and Richard Flavell (Howard Hughes Medical Institute and Yale University School of Medicine).

Received for publication June 21, 2005, and accepted in revised form July 26, 2005.

Address correspondence to: Nina Bhardwaj, New York University School of Medicine, 550 First Avenue, MSB \#507, New York, New York 10016, USA. Phone: (212) 263-5814; Fax: (212) 263-6729; E-mail: bhardn02@popmail.med.nyu.edu.

Anne-Sophie Beignon's present address is: Virologie Moléculaire et Vectorologie, Institut Pasteur, Paris, France.

Marie Larsson's present address is: Molecular Virology, Department of Molecular and Clinical Medicine, University of Health Science, Linköping, Sweden.

Anne-Sophie Beignon and Kelli McKenna contributed equally to this work.
1. McKenna, K., Beignon, A.S., and Bhardwaj, N. 2005. Plasmacytoid dendritic cells: linking innate and adaptive immunity. J. Virol. 79:17-27.

2. Kadowaki, N., et al. 2001. Subsets of human dendritic cell precursors express different toll-like receptors and respond to different microbial antigens. J. Exp. Med. 194:863-869.

3. Jarrossay, D., Napolitani, G., Colonna, M., Sallusto, F., and Lanzavecchia, A. 2001. Specialization and complementarity in microbial molecule recognition by human myeloid and plasmacytoid dendritic cells. Eur. J. Immunol. 31:3388-3393.

4. Krug, A., et al. 2001. Toll-like receptor expression reveals CPG DNA as a unique microbial stimulus for plasmacytoid dendritic cells which synergizes with CD40 ligand to induce high amounts of IL-12. Eur. I. Immunol. 31:3026-3037.

5. Ito, T., et al. 2002. Interferon-alpha and interleukin-12 are induced differentially by Toll-like receptor 7 ligands in human blood dendritic cell subsets. J. Exp. Med. 195:1507-1512.

6. Gorden, K.B., et al. 2005. Synthetic TLR agonists reveal functional differences between human TLR7 and TLR8. J. Immunol. 174:1259-1268.

7. Goutagny, N., et al. 2004. Quantification and functional analysis of plasmacytoid dendritic cells in patients with chronic hepatitis $\mathrm{C}$ virus infection. J. Infect. Dis. 189:1646-1655.

8. Hishizawa, M., et al. 2004. Depletion and impaired interferon-alpha-producing capacity of blood plasmacytoid dendritic cells in human T-cell leukaemia virus type I-infected individuals. Br. J. Haematol. 125:568-575

9. Dalloul, A., et al. 2004. Severe herpes virus (HSV-2) infection in two patients with myelodysplasia and undetectable NK cells and plasmacytoid dendritic cells in the blood. J. Clin. Virol. 30:329-336.

10. Pichyangkul, S., et al. 2003. A blunted blood plasmacytoid dendritic cell response to an acute systemic viral infection is associated with increased disease severity. J. Immunol. 171:5571-5578.

11. Soumelis, V., et al. 2001. Depletion of circulating natural type 1 interferon-producing cells in HIVinfected AIDS patients. Blood. 98:906-912.

12. Feldman, S., et al. 2001. Decreased interferon-alpha production in HIV-infected patients correlates with numerical and functional deficiencies in circulat- ing type 2 dendritic cell precursors. Clin. Immunol. 101:201-210

13. Chehimi, J., et al. 2002. Persistent decreases in blood plasmacytoid dendritic cell number and function despite effective highly active antiretroviral therapy and increased blood myeloid dendritic cells in HIV-infected individuals. J. Immunol. 168:4796-4801.

14. Barron, M.A., Blyveis, N., Palmer, B.E., MaWhinney, S., and Wilson, C.C. 2003. Influence of plasma viremia on defects in number and immunophenotype of blood dendritic cell subsets in human immunodeficiency virus 1 -infected individuals. J. Infect. Dis. 187:26-37.

15. Donaghy, H., Gazzard, B., Gotch, F., and Patterson, S. 2003. Dysfunction and infection of freshly isolated blood myeloid and plasmacytoid dendritic cells in patients infected with HIV-1. Blood. 101:4505-4511.

16. Otero, M., et al. 2003. Peripheral blood dendritic cells are not a major reservoir for HIV type 1 in infected individuals on virally suppressive HAART. AIDS Res. Hum. Retroviruses. 19:1097-1103.

17. Siegal, F. 2003. Interferon-producing plasmacytoid dendritic cells and the pathogenesis of AIDS. Res. Initiat. Treat. Action. 8:10-13.

18. Anthony, D.D., et al. 2004. Selective impairments in dendritic cell-associated function distinguish hepatitis $\mathrm{C}$ virus and HIV infection. J. Immunol. 172:4907-4916.

19. Pacanowski, J., et al. 2004. Early plasmacytoid dendritic cell changes predict plasma HIV load rebound during primary infection. J. Infect. Dis. 190:1889-1892.

20. Levy, J.A., Scott, I., and Mackewicz, C. 2003. Protection from HIV/AIDS: the importance of innate immunity. Clin. Immunol. 108:167-174.

21. Fonteneau, J.F., et al. 2004. Human immunodeficiency virus type 1 activates plasmacytoid dendritic cells and concomitantly induces the bystander maturation of myeloid dendritic cells. J. Virol. 78:5223-5232.

22. Lund, J.M., et al. 2004. Recognition of singlestranded RNA viruses by Toll-like receptor 7. Proc. Natl. Acad. Sci. U. S. A. 101:5598-5603.

23. Diebold, S.S., Kaisho, T., Hemmi, H., Akira, S., and Reis e Sousa, C. 2004. Innate antiviral responses by means of TLR7-mediated recognition of singlestranded RNA. Science. 303:1529-1531.

24. Heil, F., et al. 2004. Species-specific recognition of single-stranded RNA via toll-like receptor 7 and 8 . Science. 303:1526-1529.

25. Krug, A., et al. 2004. Herpes simplex virus type 1 activates murine natural interferon-producing cells through toll-like receptor 9. Blood. 103:1433-1437.

26. Hochrein, H., et al. 2004. Herpes simplex virus type- 1 induces IFN-alpha production via Toll-like receptor 9-dependent and-independent pathways. Proc. Natl. Acad. Sci. U. S. A. 101:11416-11421.

27. Lund, J., Sato, A., Akira, S., Medzhitov, R., and Iwasaki, A. 2003. Toll-like receptor 9-mediated recognition of Herpes simplex virus- 2 by plasmacytoid dendritic cells. J. Exp. Med. 198:513-520.

28. Krug, A., et al. 2004. TLR9-dependent recognition of MCMV by IPC and DC generates coordinated cytokine responses that activate antiviral NK cell function. Immunity. 21:107-119.

29. Abe, T., et al. 2005. Involvement of the Toll-like receptor 9 signaling pathway in the induction of innate immunity by baculovirus. J. Virol. 79:2847-2858.

30. Hornung, V., et al. 2004. Replication-dependent potent IFN-alpha induction in human plasmacytoid dendritic cells by a single-stranded RNA virus. J. Immunol. 173:5935-5943.

31. Barchet, W., et al. 2005. Dendritic cells respond to influenza virus through TLR7- and PKR-independent pathways. Eur. J. Immunol. 35:236-242.

32. Lopez, C.B., et al. 2004. TLR-independent induction of dendritic cell maturation and adaptive immunity by negative-strand RNA viruses. J. Immunol. 173:6882-6889.

33. Dornadula, G., Zhang, H., Shetty, S., and Pomerantz, R.J. 1999. HIV-1 virions produced from replicating peripheral blood lymphocytes are more infectious than those from nonproliferating macrophages due to higher levels of intravirion reverse transcripts: implications for pathogenesis and transmission. Virology. 253:10-16.

34. Capobianchi, M.R., et al. 1992. Recombinant glycoprotein 120 of human immunodeficiency virus is a potent interferon inducer. AIDS Res. Hum. Retroviruses. 8:575-579.

35. Francis, M.L., and Meltzer, M.S. 1993. Induction of IFN-alpha by HIV-1 in monocyte-enriched PBMC 
requires gp120-CD4 interaction but not virus replication. J. Immunol. 151:2208-2216.

36. Ankel, H., Westra, D.F., Welling-Wester, S., and Lebon, P. 1998. Induction of interferon-alpha by glycoprotein D of herpes simplex virus: a possible role of chemokine receptors. Virology. 251:317-326.

37. Milone, M.C., and Fitzgerald-Bocarsly, P. 1998. The mannose receptor mediates induction of IFN-alpha in peripheral blood dendritic cells by enveloped RNA and DNA viruses. J. Immunol. 161:2391-2399.

38. Zeng, J., Fournier, P., and Schirrmacher, V. 2002. Stimulation of human natural interferon-alpha response via paramyxovirus hemagglutinin lectincell interaction. J. Mol. Med. 80:443-451.

39. Yonezawa, A., et al. 2003. Natural alpha interferonproducing cells respond to human immunodeficiency virus type 1 with alpha interferon production and maturation into dendritic cells. J. Virol. 77:3777-3784.

40. Grouard, G., et al. 1997. The enigmatic plasmacytoid $T$ cells develop into dendritic cells with interleukin (IL)-3 and CD40-ligand. J. Exp. Med. 185:1101-1111.

41. Penna, G., Sozzani, S., and Adorini, L. 2001. Cutting edge: selective usage of chemokine receptors by plasmacytoid dendritic cells. J. Immunol. 167:1862-1866.

42. Turville, S.G., et al. 2002. Diversity of receptors binding HIV on dendritic cell subsets. Nat. Immunol. 3:975-983.

43. Sorg, R.V., Kogler, G., and Wernet, P. 1999. Identification of cord blood dendritic cells as an immature CD11c-population. Blood. 93:2302-2307.

44. Stent, G., et al. 2002. Heterogeneity of freshly isolated human tonsil dendritic cells demonstrated by intracellular markers, phagocytosis, and membrane dye transfer. Cytometry. 48:167-176.

45. Fonteneau, J.F., et al. 2003. Activation of influenza virus-specific CD4+ and CD8+ T cells: a new role for plasmacytoid dendritic cells in adaptive immunity. Blood. 101:3520-3526.

46. Kuhmann, S.E., and Moore, J.P. 2004. HIV-1 entry inhibitor entrances. Trends Pharmacol. Sci. 25:117-120.

47. Klasse, P.J., and Moore, J.P. 2004. Is there enough gp120 in the body fluids of HIV-1-infected individuals to have biologically significant effects? Virology. 323:1-8.

48. Durrbach, A., Louvard, D., and Coudrier, E. 1996. Actin filaments facilitate two steps of endocytosis. J. Cell Sci. 109:457-465.

49. Vendeville, A., et al. 2004. HIV-1 Tat enters T cells using coated pits before translocating from acidified endosomes and eliciting biological responses. Mol. Biol. Cell. 15:2347-2360.

50. Lee, J., et al. 2003. Molecular basis for the immunostimulatory activity of guanine nucleoside analogs: activation of Toll-like receptor 7. Proc. Natl. Acad. Sci. U. S. A. 100:6646-6651.

51. Heil, F., et al. 2003. The Toll-like receptor 7 (TLR7)specific stimulus loxoribine uncovers a strong relationship within the TLR7, 8 and 9 subfamily. Eur.J. Immunol. 33:2987-2997.
52. Manzel, L., Strekowski, L., Ismail, F.M., Smith, J.C., and Macfarlane, D.E. 1999. Antagonism of immunostimulatory CPG-oligodeoxynucleotides by 4 aminoquinolines and other weak bases: mechanistic studies. J. Pharmacol. Exp. Ther. 291:1337-1347.

53. Rutz, M., et al. 2004. Toll-like receptor 9 binds single-stranded CpG-DNA in a sequence- and $\mathrm{pH}$ dependent manner. Eur. J. Immunol. 34:2541-2550.

54. Honda, K., et al. 2005. Spatiotemporal regulation of MyD88-IRF-7 signalling for robust type-I interferon induction. Nature. 434:1035-1040.

55. Guo, J., et al. 2000. Zinc finger structures in the human immunodeficiency virus type 1 nucleocapsid protein facilitate efficient minus- and plusstrand transfer. J. Virol. 74:8980-8988.

56. Vollmer, J., et al. 2004. Characterization of three $\mathrm{CpG}$ oligodeoxynucleotide classes with distinct immunostimulatory activities. Eur. J. Immunol. 34:251-262.

57. Kerkmann, M., et al. 2005. Spontaneous formation of nucleic acid-based nanoparticles is responsible for high interferon-alpha induction by CPG-A in plasmacytoid dendritic cells. J. Biol. Chem. 280:8086-8093.

58. Karlin, S., Doerfler, W., and Cardon, L.R. 1994. Why is CPG suppressed in the genomes of virtually all small eukaryotic viruses but not in those of large eukaryotic viruses? J. Virol. 68:2889-2897.

59. Le Blanc, I., et al. 2005. Endosome-to-cytosol transport of viral nucleocapsids. Nat. Cell Biol. 7:653-664.

60. Latz, E., et al. 2004. TLR9 signals after translocating from the ER to CPG DNA in the lysosome. Nat. Immunol. 5:190-198.

61. Leifer, C.A., et al. 2004. TLR9 is localized in the endoplasmic reticulum prior to stimulation. J. Immunol. 173:1179-1183.

62. Goodman, M.G., and Goodman, J.H. 1994. Topology of the loxoribine binding site. Studies with inactive loxoribine analogues. J. Immunol. 153:4081-4087.

63. Stunz, L.L., et al. 2002. Inhibitory oligonucleotides specifically block effects of stimulatory CPG oligonucleotides in B cells. Eur. J. Immunol. 32:1212-1222.

64. Gursel, I., et al. 2003. Repetitive elements in mammalian telomeres suppress bacterial DNA-induced immune activation. J. Immunol. 171:1393-1400.

65. Leadbetter, E.A., et al. 2002. Chromatin-IgG complexes activate B cells by dual engagement of IgM and Toll-like receptors. Nature. 416:603-607.

66. Boule, M.W., et al. 2004. Toll-like receptor 9-dependent and -independent dendritic cell activation by chromatin-immunoglobulin G complexes. J. Exp. Med. 199:1631-1640.

67. Jurk, M., et al. 2004. Selective inhibition of Toll-like receptor-mediated signalling by inhibitory oligodeoxynucleotides [abstract]. 12th International Congress of Immunology and 4th Annual Conference of FOCIS. July 18-23. Montreal, Quebec, Canada. Clin. Invest. Med. 27:2333.

68. Shirota, H., Gursel, I., Gursel, M., and Klinman, D.M. 2005. Suppressive oligodeoxynucleotides protect mice from lethal endotoxic shock. J. Immunol. 174:4579-4583.

69. Elias, F., et al. 2003. Strong cytosine-guanosine-inde- pendent immunostimulation in humans and other primates by synthetic oligodeoxynucleotides with PyNTTTTGT motifs. J. Immunol. 171:3697-3704.

70. Hornung, V., et al. 2005. Sequence-specific potent induction of IFN-alpha by short interfering RNA in plasmacytoid dendritic cells through TLR7. Nat. Med. 11:263-270.

71. Granelli-Piperno, A., Golebiowska, A., Trumpfheller, C., Siegal, F.P., and Steinman, R.M. 2004. HIV-1infected monocyte-derived dendritic cells do not undergo maturation but can elicit IL-10 production and T cell regulation. Proc. Natl. Acad. Sci. U. S. A. 101:7669-7674.

72. Marechal, V., et al. 2001. Human immunodeficiency virus type 1 entry into macrophages mediated by macropinocytosis. J. Virol. 75:11166-11177.

73. Schaeffer, E., Soros, V.B., and Greene, W.C. 2004. Compensatory link between fusion and endocytosis of human immunodeficiency virus type 1 in human CD4 T lymphocytes. J. Virol. 78:1375-1383.

74. Patterson, S., Rae, A., Hockey, N., Gilmour, J., and Gotch, F. 2001. Plasmacytoid dendritic cells are highly susceptible to human immunodeficiency virus type 1 infection and release infectious virus. J. Virol. 75:6710-6713.

75. Fong, L., Mengozzi, M., Abbey, N.W., Herndier, B.G., and Engleman, E.G. 2002. Productive infection of plasmacytoid dendritic cells with human immunodeficiency virus type 1 is triggered by CD40 ligation. J. Virol. 76:11033-11041.

76. Vollmer, J., et al. 2004. Modulation of CPG oligodeoxynucleotide-mediated immune stimulation by locked nucleic acid (LNA). Oligonucleotides. 14:23-31.

77. Jurk, M., et al. 2002. Human TLR7 or TLR8 independently confer responsiveness to the antiviral compound R-848 [letter]. Nat. Immunol. 3:499.

78. Yasuda, K., et al. 2005. Endosomal translocation of vertebrate DNA activates dendritic cells via TLR9dependent and -independent pathways. J. Immunol. 174:6129-6136.

79. Lu, W., Arraes, L.C., Ferreira, W.T., and Andrieu, J.M. 2004. Therapeutic dendritic-cell vaccine for chronic HIV-1 infection. Nat. Med. 10:1359-1365.

80. Ott, D.E., Nigida, S.M., Jr., Henderson, L.E., and Arthur, L.O. 1995. The majority of cells are superinfected in a cloned cell line that produces high levels of human immunodeficiency virus type 1 strain MN. J. Virol. 69:2443-2450.

81. Arthur, L.O., et al. 1998. Chemical inactivation of retroviral infectivity by targeting nucleocapsid protein zinc fingers: a candidate SIV vaccine. AIDS Res. Hum. Retroviruses. 14(Suppl. 3):S311-S319.

82. Chertova, E., et al. 2002. Envelope glycoprotein incorporation, not shedding of surface envelope glycoprotein (gp120/SU), is the primary determinant of SU content of purified human immunodeficiency virus type 1 and simian immunodeficiency virus. J. Virol. 76:5315-5325.

83. Bess, J.W., Jr., Gorelick, R.J., Bosche, W.J., Henderson, L.E., and Arthur, L.O. 1997. Microvesicles are a source of contaminating cellular proteins found in purified HIV-1 preparations. Virology. 230:134-144. 